\title{
Morale and Mass Observation: Governing the Affective Atmosphere on the Home-Front
}

\author{
${ }^{*}$ Ben Dibley, **Michelle Kelly
}

\begin{abstract}
This paper focuses on Mass Observation (MO)'s morale work, commissioned by the British Government over the period 1939-41. It examines the ways in which MO's earlier collecting practices were recomposed through its research into civilian morale, and linked up with national centres of calculation, in particular the Ministry of Information (Mol). We explore the associations through which civilian morale was established, simultaneously, as an autonomous object of knowledge and as a particular field of intervention. As an object of knowledge, morale posited the existence of a dynamic affective 'atmosphere' associated with collective everyday life, which could be calibrated through various social scientific methods. As a particular field of intervention, technicians of morale postulated that this atmosphere might be regulated through various policy instruments. This paper traces the ways in which MO practices were implicated along these two axes in the emergence of civilian morale as a domain warranting the state's 'constant attention and supervision'.
\end{abstract}

Keywords: Mass Observation, civilian morale, liberal governmentality.

[Mass-Observers] will be the meteorological stations from whose reports a weather-map of popular feeling can be compiled.

Charles Madge and Tom Harrisson, Mass-Observation (1937: 30)

The government should be fully aware of all the trends in civilian morale. They need an accurate machine for measuring such trends; a war barometer.

Mass Observation, War Begins at Home (1940: v)

Focusing on Mass Observation (MO)'s morale work commissioned by the British Government over the period 1939-41, this paper examines how the organization's early practices of data collection were recomposed and linked up with national centres of calculation - in particular, the Ministry of Information (Mol). Investigating Mass Observation's work for the Ministry, the paper traces how civilian morale was established, simultaneously, as an autonomous object of knowledge and as a field of intervention. As an object of knowledge, morale posited the existence of a dynamic affective 'atmosphere' associated with collective everyday life which could be calibrated through various social scientific methods. ${ }^{1}$ As a field of intervention it was postulated that this atmosphere, if its dynamics were properly understood, could be regulated through various policy instruments, from programmes of propaganda to policies of compulsion directed variously at rumour and 'dangerous talk'; gasmask carrying; evacuation planning; post-Blitz recovery, and so on. To this end this paper reviews how Mass Observation practices were implicated in the emergence of morale as an affective atmosphere warranting the state's 'constant attention and supervision' (MO 1940, War Begins at Home: 419).

We proceed in two parts. The first considers the emergence of civilian morale as an entity which rendered the affective atmosphere of wartime Britain knowable and so manipulable. 
This involves the ways in which morale came to designate a general psycho-social condition whose contours could be made visible in various knowledge formulations concerned with 'the public mind' and 'private opinion'. The concern here is with the contexts in which morale emerged as a new 'transactional reality' mediating relations between the governing and the governed. This section, then, addresses the question: How did the subjective disposition of a population emerge as this object of intense scrutiny: that is, what was the problematic in which morale emerged as an answer?

The second part considers the particular techniques of persuasion and compulsion advanced by $\mathrm{MO}$ to target morale and the respective relations of these different techniques to the problematic of liberal government (Foucault 2008). Drawing on the recommendations put forward by $\mathrm{MO}$ in both its evaluations of existing levels of morale and its assessments of the instruments for intervening in those levels in particular urban contexts, this section considers how the government of morale was implicated in different modalities of power. Firstly, as it exercised a form of bio-power concerned with the productivity and sacrifice of the civilian body. Secondly, as it walked a line between liberal and illiberal forms of rule in which the administration of morale oscillated between a concern with the responsibilisation of the citizen-subject's freedom and more directly coercive measures. Thirdly, as it targeted working class populations through two different modes of government, cf., those whose mechanisms worked via 'the public' by appealing to the voluntary actions of the citizenry, and, those that operate via 'the milieu', altering the material environment in which that citizenry body is situated. This section, then, is concerned with how morale came to be folded into the problematic of liberal rule. In particular, with 'the agenda and non-agenda' of morale policy (Foucault 2008: 12 ) - that is, with the question of what could safely be the subject of intervention on the one hand, and on the other, as historian of the Mol, lan McLaine, put it 'what it was best to leave alone' (1979: 10). ${ }^{2}$

MO completed its first report for the Mol upon the outbreak of war in September 1939, and delivered its final Ministerial 'collaboration' in November 1941 (Hubble 2006: 167, 187). ${ }^{3}$ The work for the Ministry represented a new kind of application for the quotidian investigations of the organization founded in 1937 by Tom Harrisson, Charles Madge and Humphrey Jennings, who had energetically imagined that MO's work would be significantly distinct from other social science research. ${ }^{4}$ Writing in 1971, Harrisson reflected upon the 'double-sided approach' which distinguished the MO method: firstly, observation of fellow citizens by 'trained mass-observers' and, secondly, a panel of volunteers who could contribute 'personal documentation and random observation', in practice through diaries and survey and directive responses (1971: 398-9). These instruments which had, in peacetime, aimed to gather data on the 'habit, emotion, opinion' of the masses were recomposed and, as part of the Mol work, redirected at morale (MO 1944, \#2116: [10]). ${ }^{5}$ In 1942 Bob Willcock - then director of MO - suggested that the 'complex machinery' MO developed for measuring 'people's behaviour, their subjective feelings, their worries, frustrations, hopes, desires, expectations and fears' was in fact 'strengthened by the experience of war', resulting in its increasing refinement as a method of data collection (MO 1942, \#1415: 21-2).

The ethnographically informed epistemic procedures and collecting practices implicated in MO's data gathering machinery have a museological dimension which was significant for the project's involvement in the government of morale. In observing how 'MO framed its project as a "museological" one', Rodney Harrison (2014: 228) has drawn out the ways in which MO brought together ethnographic methods of collecting and assembling with mechanisms of individual and collective self-watching. These mechanisms were central to the development of public museums as spaces of liberal government, as Tony Bennett $(1995 ; 2004)$ demonstrates; and key to the emergence of public archives as spaces 'intimately concerned with collecting information about the condition of "the people"', in Patrick Joyce's argument, and so necessarily implicated in the formation of the liberal subject as one of self-surveillance and self-government (1999: 40). The question which emerges is how did Mass Observation turn to morale to provide a governmental optic on the condition of the Britain's civilian population? ${ }^{6}$ 


\section{The Morale Problematic: Total war and the 'atmosphere of ordinary Britain'7}

The fortifications of our minds ... without constant attention and supervision by skilled and trained technicians ... remain the fortifications of pre-war. But Nazi Germany lead the world in mind-sweeping, and morale-influencing.

Mass Observation, War Begins at Home (1940: 419; emphasis in original) ${ }^{8}$

As modernity's quintessential total war, WWII was 'the first global aerial war' 9 in which both the Allies and the Axis strategies were directed as much at 'the morale of the civilian populations of the enemy nations' as they were at strictly military targets - devastatingly through air-raids and deviously through airwaves (Osborne and Rose 1999: 380). As such, morale was identified as an element intimately linked to 'the military fortunes of a nation' and was increasingly thought of in strategic terms (380). If morale was being assailed by the nation's enemies, the state must be able to protect, preserve and promote it. If morale was to be so fostered, the state needed 'to assess it and understand it, in order to develop, adjust and evaluate policies towards it' (380). The question arises, then: how did the emotional disposition of the civilian population emerge as this object of intense administrative scrutiny and military salience?

To begin to address this question it is useful to turn to an analytics of government. This is an analytics concerned with the epistemic and the administrative procedures through which particular entities come to be. On Mitchell Deans' characterization, it is a mode of inquiry 'concerned with an analysis of the specific conditions under which particular entities emerge, exist and change' (1999: 20-1). Central to this analytics is Foucault's notion of 'transactional realities' (réalité de transaction) (2008: 297). With this term Foucault designates:

those transactional and transitional figures that we call civil society, madness, and so on, which, although they have not always existed are nonetheless real, [and] are born precisely from the interplay of relations of power and everything which constantly eludes them, at the interface, so to speak, of governors and governed (297).

This section focuses on the conditions under which morale came to be - concentrating on the emergence of the apparatus that bought this entity into existence; stabilizing it as an object of knowledge; and intervening in it as a field of government. This section, then, is concerned with the forms of knowledge that made morale visible and rendered it calculable and programmable such that it came to serve as an interface between the governors and the governed in wartime Britain. It takes as its point of departure the contention that the emergence of morale was simultaneously a morale emergency.

In 1938 a committee of psychiatrists submitted a report to the British Ministry of Health, which considered the psychological consequences of the sustained bombing of civilian populations. The report anticipated:

the psychiatric would exceed the physical casualties by three to one, which, on the basis of the government's estimates of killed and wounded, would mean between three and four million cases of acute panic, hysteria and neurosis during the first six months of war (McLaine 1979: 26).

With these predictions the report confirmed the doxa that had been established in the mental health profession by the mid-1920s, where evidence from the 1914-18 war came to confirm the inevitability of an epidemic of neurosis among civilians as a result of air attack. Faced with these prospects the report called for a complex and extensive psychiatric apparatus to minister to the psychologically shattered. However, preparation for the remedial was not the only strategy anticipating this epidemic. Equally pressing was a consideration of the prophylactic measures that might fortify 'the public mind' against an air war intent on breaking civilian morale to the point of capitulation.

If the Ministry of Health was charged with anticipating the psychiatric consequences of air war, it was the Ministry of Information that was accorded responsibility for the pre-emption of these effects. This Ministry, if it was to protect morale against the damaging psychological 
consequences of air raids, needed to come to know the emotional life of the civil population, its 'group feeling', if that life was to be rendered calculable and securable. On Nikolas Rose's account this is the precise moment of 'the birth of a social psychiatry'; one registered in the Lancet in August 1940 by the director of the London Clinic of Psychoanalysis, Edward Clover:

For the first time in history a government has officially recognized that the state of public opinion is as important an index of the health of the community as a full anamnesis in the case of individual illness ... the Ministry of Information has established that group feeling is a medico-psychological concern and that it calls for instruments of precision in diagnosis (cited in Rose 1998: 134).

In the event, the psychiatrists' predications failed to eventuate. There was no significant increase in neurosis or other mental illnesses evident during the war in Britain. As another mental health practitioner put it: 'The incidence of genuine psychiatric air-raid casualties has been much lower than might have been expected; the average previously healthy citizen has proved remarkably adjustable' (Felix Brown, cited in McLaine 1979: 108). While these anxieties of mass neurosis proved unfounded, they did nevertheless have their own effects: the emotional landscape of the civilian population emerged as a zone of intense governmental scrutiny. Numerous inscription devices collated the link between morale and bombing and translated this relationship into calculable forms in reports, statistics, graphs and other documentation - together this contributed to an emerging apparatus with an increasing capacity to map the population's emotional topography. The Ministry of Information was key to this process, as both a centre of collection and of calculation. ${ }^{10}$

Yet, as documentation from the Ministry made clear, assembling morale's diagnostic instruments was no simple matter. It faced a significant challenge: precisely, how was civilian morale to be rendered knowable and, consequently, made actionable? As McLaine summed it, the Ministry was 'working in virtually uncharted territory' (1979: 23). The answer saw the development of 'machinery for the collection of intelligence' in the form of the Collecting Division (subsequently Home Intelligence), whose brief was to provide a constant monitoring and assessment of civilian morale and to distribute this information to other government departments (22).

Charged with this injunction to know the subjective interiority of the civilian population so that it might be linked to objectives of the state, in 1940 the newly appointed director of the Mol's Collecting Division, Mary Adams, proposed the creation of a 'morale barometer' (cited in Hubble 2006: 179-80). Outlining her proposals for 'the structure and functions' of this division, Adams identified that: '[Its] immediate tasks were to supply the Ministry [Mol] itself with routine monthly and ad hoc reports on matters of urgency and on the effectiveness of propaganda'. As she added: 'A continuous flow of information is required ... to study immediate reactions to specific events as well as to create a barometer for the measurement of opinion, on questions likely to be continuously important' (cited in McLaine 1979: 50).

There were three primary sources that the Mol drew upon in its enterprise to turn morale into writing and make it legible' (Rose 1990: 28-9): its own Home Intelligence/Collecting Division, which itself gathered data from various sources including regional staff with local contacts, the BBC Listeners' Research Unit, the Postal and Telegraph Censors and police duty room reports; the National Institute for Economic and Social Research's Wartime Social Survey (WSS); and, in spite of 'some disquiet concerning its methods', Mass Observation - in fact the initiative leading to the establishment of the WSS was 'to act as a check' on MO data (Hubble 2006: 179). However, as McLaine notes, 'the Ministry placed a heavy reliance on the work performed by Mass-Observation' in spite of these reservations (1979: 52). Indeed, Adams was to convey to Treasury that MO reports 'have now become an essential part of the whole machinery of Home Intelligence' (cited in Hubble 2006: 182). In this, then, MO came to make a significant contribution to this organization, assisting in the Mol's 'duty ... to [interpret] the public mind to the Government, and act as [a] clearing house for information about changing habits and beliefs' (MO 1940, \#507: 4).

In supplying its expertise to the Mol's emerging 'morale barometer', MO's work with the Ministry took place in the context of, and contributed to, the processes through which citizenship had 'acquired a subjective form' (Rose 1990: 32). MO turned to the calibration 
of the affective atmosphere of wartime Britain and became imbricated in 'the transactional reality' that emerged as civilian morale. Summarizing the developments in Britain over the late 1930s and 1940s, Rose writes: 'From this point forth, winning the war, and winning the peace, required the active engagement of the civilian in the social and political process, a shaping of wills, consciences, and aspirations, to forge social solidarity and individual responsibilities' (32). He continues: 'As citizenship became a psychological matter, the psyche of the citizen was discovered as a new continent for psychological knowledge and for the deployment of the professional skills of the technicians of subjectivity' (32). Morale emerged as a key mechanism by which the governors might get a hold of this newly defined psycho-social territory, and so optimize the wellbeing of the citizenry while simultaneously serving the national interest and war effort. In linking up its expertise on the subjectivity of the ordinary people with the state apparatus, $\mathrm{MO}$ was implicated in the conquest of this continental discovery: the psyche of the citizenry - 'the mysterious, unfathomed depths of consciousness which the Government must learn to understand and exploit' (MO 1940, \#298: 12). ${ }^{11}$ Or, as it was termed by MO, 'the public mind' (MO 1941, \#568: [1]). ${ }^{12}$

\section{The Stratified Subject: 'The public mind' and the production of subjectivity}

... to get at the public mind ... we must distinguish several levels of opinion and behaviour.

Mass Observation, 'What is Public Opinion?' (1940, \#361: 9)

As posited by $\mathrm{MO}$, the subject of morale was stratified: it was a subject of surface and depth. In its formulation of morale, $\mathrm{MO}$ documentation was at pains to draw a qualitative difference between public and private opinion - a distinction which it contended was consequential for the measurement and interpretation of morale. One report claimed: 'In generalisations about morale, one must always bear in mind the vital difference between what people say, and especially what they say to a stranger (the interviewer), and what they are thinking deep down' (MO 1940, \#89: [1]). In this, a methodological problematic was established which highlighted the limitations of procedures that would rely solely on public opinion to gauge morale. Refining MO's 'investigative machinery', a subsequent report to the Mol advanced an analysis precisely in terms of surfaces and depths. It contended:

[The reported] generalisations are essentially based on detailed facts, but also go below the surface layer of these facts. That is now an essential part of understanding morale. It has always been very misleading to rely on material of the interview and spoken comment type. That has never given more than public opinion[;] the done thing .... It is private opinion which matters (MO 1940, \#222: 16).

This notion of morale, then, posited the citizen-subject not only as the bearer of surfaces and depths, but as one whose psychological veracity was only to be discovered in the latter. Harrisson's academic publications of the time similarly worked to formalize this distinction between public and private opinion so that it was the interiority of the private, over the exteriority of the public, which had privileged access to the truth of morale. In contrast to the emerging methodological tools of British sociology - the social survey and the opinion poll, which offered competing cartographies of citizen subjectivity to MO's more qualitative approaches ${ }^{13}$ - exponents of MO's method lay claim to the expertise required to penetrate the interiorities of the citizen-subject, and so to lay bare the truth of what was hidden: the 'unfathomed depths of consciousness' of the ordinary Briton (MO 1940, \#298: 12). And with it, the precise state of the subjectivity that lay under the mask of public opinion, which the government must access and exploit.

It is important to register what is at stake in this distinction between 'public opinion' and that which lies beneath, 'private opinion'. In this formulation Harrisson looked to discredit the object of his social scientific rivals: public opinion. ${ }^{14}$ 'Public opinion' could only ever be a poor optic on morale; rather, the proper task of the social analyst was to understand the 
dynamics of 'private opinion' and its public manifestations and implications. But more than this, 'public opinion' was not only a weak indicate of actual morale; it also had the potentiality to be dangerously repressive:

Civilian morale is to-day acclaimed byAdmirals, Mayors, Ministers and journalists, as $\mathrm{A} 1$... this ballyhoo sanctions only a show of pleasure or reprisal, and makes it more difficult for people to express perfectly natural feelings of depression or distress. More and more, in recent months, emotions have been bottled up, and the [gulf] between public opinion and private opinion is again becoming dangerously enlarged .... The more compulsion and restriction, the more easily can tensions develop at the level of private opinion without ever being noticed on top. In such situations we have the elements of violent explosion, quite 'unexpectedly' released at some crisis moment (MO 1941, \#568: 56, 66).

The 'good government' of morale was the management and minimization of the dissonance between public and private opinion, between external and 'superficial' public expression and internal and 'deep' private countenance, such that this volatile pressure did not gather in the affective atmosphere, and explode in an uncontrolled manner detrimental to both the individual subject and social order. A lack of understanding and a failure to 'grasp' the disposition of ordinary citizens was a recurring and prominent charge in the $\mathrm{MO}$ documentation against the nation's political elites, with the governors regularly chastised for their inadequate knowledge of the governed and thus their poor management of civilian morale:

The whole situation of morale at the moment is dominated by the continuing lack of precise leadership .... Ministers and the Ministry of Information continue to show themselves emotionally unaware [and] administratively unready to handle or canalise the immensely powerful feelings which are surging beneath the surface of practically every individual in the island (1940, \#242: [7]). ${ }^{15}$

MO's research thus developed a precise correspondence between an exigency of Britain's wartime government, and the subject of MO's expertise, cultivating the emergence of morale as a previously obscured object of knowledge in service of rehabilitating a nation in crisis.

\section{Governing Morale:}

\section{The Problematic of Liberal Government: Morale and political rationality}

We believe, from the material in this book, and from a great deal of other material which we have collected in the last two years, that the Government cannot afford to leave the civilian population without powerful leadership and constant attention.

Mass Observation, War Begins at Home (1940: 421)

This section is concerned with the political rationality of morale, specifically, the ways morale was figured in relation to the problematic of liberal government which, historically, has been constituted in the 'principle of the self-limitation of government': that of governing too little and too much (Foucault 2008: 19-21). We turn to MO arguments which consider how 'good morale' can be served, variously, by both policies of persuasion and compulsion. Here effective, efficient government of civilian morale was deemed to be that, which, in understanding the dynamics of 'the public mind', and comprehending 'its inherent nature', knows when liberal mechanisms of persuasion must give way to authoritarian forms of rule (and vice versa) if that mind is to be, simultaneously, relieved of its 'bewilderment', 'panic' and 'uncertainty' - characterized in the extreme by the atmosphere of blitzed cities - and, focused on the 'endurance', 'hard work' and 'energy' necessary to optimize the productivity of the war economy. ${ }^{16}$

Morale and Life Itself: 'The public mind' and the bio-political

It is bad morale to endanger your productive capacity, even if you are cheerful and heroic while you do it. 
Tyrus Miller has suggested that MO's 'Dream Project' - an investigation which sought to collect and analyze the dreams of ordinary citizens - was a project concerned with 'the affective experience of biopolitical governmentality' (2001: 42). This is a useful formulation to draw on in relation to MO's work on 'the public mind' and morale. All the more so, in that as MO refined the concept of morale its affective dimensions were linked with explicitly bio-political concerns targeting 'life itself'. That is, on the one hand, with the productivity of the population's labourpower and the responsibility of the citizenry for prudence with regard to the preservation of life; and, on the other, with the cultivation of a preparedness for self-sacrifice in the interests of that aggregate. The first of these dimensions is illustrated in a 1941 report for the Mol, where the question 'what is good morale?' was answered in the following terms. Good morale involved 'maintaining and producing an offensive spirit as well as a defensive spirit', with an economic inflection added to the psychological definition: 'primarily good morale to-day means hard work' (MO 1941, \#568: 6-8). In this way morale was linked to 'efficiency', understood 'as gaining the maximum war effort from the population' (Beaven and Griffiths 1999: 75).

If civilian morale was a mechanism by which to extract surplus from the population in conditions of a war economy, it was also a mechanism which hailed the prudent subject. In the same document, good morale was identified (at least in part) as a defence against risky behaviour which would imperil the citizen-worker's body - that biological substrate for 'hard work' - and, thus, the potentiality of that subject's labour-power: ${ }^{17}$

It must be the responsibility of leadership to get the citizens to take precautions in their own interests. If they are failing to take the precautions there is something badly wrong. At present, for instance, on the whole absence of gasmask carrying is a sign of good morale. But not to carry your gasmask might equally be interpreted as bad morale. It is bad morale to endanger your productive capacity (MO 1941, \#568: 11).

However, good morale in MO's formulation is not only a mechanism that would seek to secure life by responsibilising citizens into precautionary habits so as to optimize productivity. Perhaps paradoxically, good morale also prepared the ground for the forfeiting of that life. For example, in a subsequent document morale was defined in the following terms:

By morale we mean primarily not only the determination to carry on, but also determination to carry on with the utmost energy, a determination based on a realisation of the facts and with a readiness for many minor and some major sacrifices, including, if necessary, the sacrifice of life itself (MO 1941, \#600: [i]).

Variously configured to serve the interests of the collective and, ultimately, the interests of the state, MO's affective formulations of morale had a complex, even conflicted relation with the bio-political. As the next section will demonstrate, a similar equivocality was also reflected in the organization's analysis of two modalities of rule.

Liberal and Illiberal Rule: Persuasion and compulsion

This book will frequently show conflict or confusion between the voluntary principle of peace and compulsory principle of war.

Mass Observation, War Begins at Home (1940: 1)

The State has two methods: persuasion and compulsion. It is rightly reluctant, at all times, to abandon the one and resort to the other.

Mass Observation, Home Propaganda ([1941]: [i])

MO documentation for the period with which this paper is concerned was marked by a significant level of deliberation about the effective management of morale, which would necessarily walk a line between policies of persuasion and compulsion. Here MO's knowledge 
practices became imbricated in the problematic of liberal government: a problematic, to follow Foucault's characterization, which must distinguish between practices of governing through liberal modalities of power that would seek to rule through liberty, and practices which seek to govern through other, illiberal means, marking the limits to freedom's rule. That is, in this case, practices which govern through the principle of compulsion, such as conscription, curfews, rationing, and so on. The discussion below traces the logic by which $\mathrm{MO}$ argued, on the one hand, for occasions where it was necessary to limit government in circumstances where the implementation of illiberal forms of rule generated conditions counter to the aims of good government; and, on the other, the reverse: those instances where illiberal forms of rule ought to be implemented since they were in the interests of the effective and efficient government of the population's welfare.

In 1940 the British Government campaigned and legislated against 'dangerous talk' on the grounds that 'those who spread gloom and despondency do definite harm' to civilian morale and the war effort generally (cited in MO 1940, \#286: 13). Reviewing this attempt to control rumour and despondency through legislation, MO contended that such policy was demonstrative of the governors' inadequate knowledge of working class culture. Implemented with no ethnographic understanding of the function of such talk in British society, legislation for its prohibition could only be detrimental for securing 'good morale'. Without this knowledge, policy-makers failed to recognize a key mechanism of self-regulation within that society: the role of argumentative and humorous conversation. MO maintained such conversation was a necessary 'safety valve in our culture', and as such, this mechanism by which affective energies were released was posited as something like a natural condition of civil society; cf., 'a British habit', a part of 'the British tradition' (14). In this instance, then, illiberal rule was cast as an unwarranted interference in popular conduct. Not only ineffectual and unlikely to 'defeat defeatism', it was also counter-productive to its wider aims, since it worked against civil society's own mechanisms for maintaining morale (20). The report contended that 'dangerous talk' should instead be targeted through techniques that sought to get hold of citizens' conduct via appeals to their voluntary actions; that is, through the persuasive practices of propaganda.

While propaganda was closely involved in efforts to modulate voluntary conduct, as will be considered in more detail in the next section, it was also a practice which could be used to forge a connection between liberal and illiberal modalities of power. MO reported that people were willing to forfeit freedoms when fully informed of the need for their forfeiture:

That is why this legislation has had a disturbing effect. People do not resent restrictions in wartime, so long as they know where they are and what it all means, and so long as the basic elements of freedom do not appear to be overwhelmingly involved (28).

Thus propaganda could play a role in communicating imperative; accordingly, the conditions under which citizens consented to coercion and were prepared to surrender freedoms in the interests of national security and welfare were a regular concern in $\mathrm{MO}$ documentation of the early 1940 s.

MO was active in investigating situations where illiberal forms of rule were, in its view, in the interests of good government. MO aimed to situate and quantify public tolerance for authoritarian rule, and its research sought to establish as an objective truth the existence of a demotic - if not democratic - desire for forms of compulsion in particular contexts. For example, in a MO report canvassing popular views on 'the responsibility of the citizen', it was stated: 'As the average citizen sees it, in wartime this responsibility consists mainly of doing what he is told or urgently asked to do' (1941, \#568: 9-10). Evidence for this claim pointed to MO surveys that discovered widespread support for the conscription of women's labour and other forms of compulsion in relation to evacuations, fire-spotting, air raid precautions, and so on. ${ }^{18}$ Such findings could translate into policy advice, and MO urged the Government to action in the case of fire-spotting: 'these responses suggest that the moment is ideal for the introduction of such regulations' (MO 1941, \#536: 4). Accompanying this advice was a strategic recommendation for regulation which demonstrates MO's dexterity in negotiating its seemingly paradoxical investment in liberal and illiberal rule: 'it should continue to be stressed that compulsion is only being used where the voluntary system has been tried and failed' (4). ${ }^{19}$ 
As a form of expertise in the service of the state, then, $\mathrm{MO}$ was concerned with discovering how, under conditions of total war, citizen-workers' were, on the one hand, amenable to particular practices of persuasion which sought to get a hold of subjects' conduct through their voluntary actions, and, on the other, practices directed not at free actions, but at governing through the principle of compulsion. Thus the question arises: by what mechanisms do practices that would seek to direct the citizenry through persuasion and compulsion get a hold of their conduct? The following section addresses this question by considering how morale came to target the civilian population via two mechanisms of government: the public and the milieu.

\title{
Morale Emergency: Public and milieu
}

In the event of an invasion it will be essential for the Government to be able to control the civil population absolutely - not through the police or the military, who will be largely on other work, but through the radio, through notices, through word-of-mouth instruction .... It is here that propaganda comes in.

Mass Observation, 'A New Attitude to the Problems of Civilian Morale' (1940, \#193: [1]-9)

\begin{abstract}
At present, not only is there little local lead, but the simple, material activities necessary for restoring some sort of shape to life after a blitz have been rendered too complicated by official machinery and by a frequent lack of understanding of the working-class mind in emergency.
\end{abstract}

Mass Observation, 'Summary of Talk to the British Psychological Society ... by Tom Harrisson' (1941, \#926: 6)

In Security, Population, Territory, Foucault describes two mechanisms through which a population might be governed: respectively, through practice which addresses the population as a public, and practice that attends its milieu (2007: 20-1, 75). For Foucault, the public 'is the population seen under the aspects of its opinions, ways of doing things, forms of behaviour, customs, fears, prejudices, and requirements: it is what one gets a hold on through education, campaigns and convictions' (75). The milieu is associated with the apparatus of security, which Foucault identifies as one of three mechanisms of power, alongside sovereignty and discipline. For Foucault security is the dominant contemporary mode of power, and examples of its techniques include criminal statistics and medical campaigns: it is a mechanism wherein probability, calculation and optimization are enlisted in order to administer 'an indefinite series of mobile elements' $(6,20)$. The milieu is the space in which this series emerges, and can be managed:

The milieu is a certain number of combined, overall effects bearing on all who live in it .... the milieu appears as a field of intervention in which, instead of affecting individuals as a set of legal subjects capable of voluntary actions-which would be the case of sovereignty-and instead of affecting them as a multiplicity of organisms, of bodies capable of performances, and of requited performances-as in discipline-one tries to affect, precisely, a population. I mean a multiplicity of individuals who are and fundamentally and essentially only exist biologically bound to the materiality within which they live (21).

So in contrast to governing via the public, which seeks to get hold of the population through persuasive techniques targeting habits, customs and beliefs, governing via the milieu seeks to get hold of the population by manipulating the materiality that conditions its existence. In being governed through its relations to its milieu, population, then, does not concern subjects of law, or bodies for discipline, but rather a biological aggregate with particular regularities. MO's analysis of blitzed urban centres demonstrates a population being targeted via both of these mechanisms under conditions of emergency. ${ }^{20}$

When German aerial attacks were extended to provincial English cities in November 1940, MO dispatched Observers to report on the immediate aftermath of the Blitz in various 
regional contexts. ${ }^{21}$ Mackay has observed that almost all of the reports $\mathrm{MO}$ made on blitzed provincial cities 'reveal the inadequacies of the [Government's] provision' (2002: 73). Disrupted by air raids, many citizen-workers found themselves in situations of radical uncertainty, where existing modes of conduct no longer seemed to hold. Addressing the British Psychological Society in 1941, Harrisson summarized the findings of his organization's research to date: 'In every blitzed town studied by Mass-Observation this has been a dominating feeling; one of individual relapse, bewilderment, and uncertainty as to what to do, how to behave' (MO 1941, \#926: 3). MO reports contended that in the extraordinary conditions of the blitzed city, the ordinary citizen was left without a template for behaviour. This condition of radical despondency was exasperated all the more because citizens were left without leadership - without guidance as to what was expected of them: 'There was no role for the civilian. Ordinary people had no idea what they should do' (MO 1940, \#495: 2). The effect on civilian morale Harrisson observed was shattering:

This lack of any plan or code of behaviour for the civilian in air raids gives [civilians] not only a feeling of helplessness, but also a feeling that everything is broken .... in Coventry there was among many people a helpless, hopeless sort of feeling that the town itself was killed, and there was nothing to be done but to get out of it ... 'Coventry is finished', 'Coventry is dead' (MO 1941, \#926: 4).

Harrisson opined this lack of instruction contributed directly to the irregular movement of urban populations that followed air raids and the ensuing chaos the exodus produced. 'It is largely to this [lack of instruction], and not to actual physical fear, that the terrible, random evacuation of $50 \%$ of the population ... must be attributed' (3-4). Harrisson lamented: 'If there had only been some kind of coherent direction' as to the 'accepted code of behaviour ... to follow there would have been far less alarm and depression' (3). For the authors of these reports this situation of perplexity as to how to conduct oneself in the absence of clear leadership was indicative of both: (i) the failure of present propaganda strategies and the need to build the pedagogical dimensions of morale management; and (ii) the breakdown in the mechanisms of security by which the circulation of bodies and things were to be regulated and so manage the materialities of working class life in emergency.

Firstly, then, MO articulated the authority's failure to effectively govern through the public; that is, via the persuasive techniques of propaganda that should manage a population's 'opinions, ways of doing things, forms of behaviour, customs'. In this the governors had inadequate expertise on 'the public mind' and thus suffered from a 'lack of understanding of the working-class mind in emergency' (6). In his talk to the British Psychological Society, Harrisson highlighted this gap in knowledge by emphasizing the social distance between classes. Commenting on the consequences of the Blitz on gendered, working class subjectivity, he argued:

It is hard for an average well-educated, reasonably well-off member of the middle classes to appreciate the completeness of the shock to an uneducated working-class housewife of a bad air raid. She has no country line of retreat, no car or immediate spare cash for hotel or train journey. It is not so much the actual danger involved that is important. Rather it is the total upheaval of her accepted way of life; the disappearance of the fifty-one landmarks of daily life which to her have been unalterable, part of the universe, inherent in living ... all these things have been part of the foundation of her life; she has accepted them with almost as little question as primitive man accepted the force of gravity. The disappearance of them overnight is a shattering psychological blow (2-3). ${ }^{22}$

Morale pedagogy was one strategy to fortify the civilian population. In this, it was constitutive of a process of informal education whereby citizens would come to be installed with a template for conduct so that they might come to know how to behave post-Blitz. In knowing 'what to do', the civilian population was to be supplied with a defence from the shattering psychological blows consequent on the total upheaval of ordinary life (3):23

A nation-wide campaign of blitz education for the coming winter should be undertaken. In every possible target area people should be pre-educated on the 
possible developments and how they should react to them. Existing and shadow arrangements for feeding, rest centres, evacuation and education should be publicised and registered in every citizen. Strong propaganda should be used to make it clear that these services are here to be used, and that they are designed for the benefit of the citizens (MO 1941, \#785-6: 26).

However, it can be seen that even here another strategy was also present, one that did not seek to get a hold of the population through pedagogical means, but through the materiality that conditioned life post-Blitz. As Harrisson put it, this concerned those practices that directed attention to the 'material activities necessary for restoring some sort of shape to life after a blitz' (MO 1941, \#926: 6). That is, those practices that sought to get a hold of the civilian population via the milieu.

In MO's report on the blitzed city of Coventry, MO analysts urged authorities to attend not only to those injured or killed by air raids, but to pay a greater level of attention to the homeless, and more again to the 'much larger group' who were not materially affected by the bombing but were who were (profoundly and understandably) 'immensely upset' (MO 1940, \#495: 3). The report urged that the State provide assistance to these individuals, 'linking them up again to the outside world, from which they are otherwise severed from lack of transport, lack of telephones, destruction of local press, destruction of electricity and thus of many radio sets'; the report criticized the fact that 'there were virtually no buses running' even though the streets had been cleared of debris with great efficiency; it suggested morale would be strengthened if 'mobile canteens which had been waiting outside the town had come moving in through the streets' $(4,5,7)$. In MO reports on blitzed cities, the number of recommendations which relate to circulation is striking. In foregrounding the movement of bodies, commodities and communications and exhorting their urgent restoration as part of the rehabilitation of blitzed cities, the importance of these flows in conditioning the terrain in which morale was determined is revealed. ${ }^{24}$

In intervening in blitzed urban centres the management of morale was to be folded into a form of social governance that sought to act on the population via its milieu. While these strategies were deployed simultaneously with those that addressed the population as a public, they worked not through persuasive appeal, but by interventions into the movement of bodies and things so as to secure their circulation and - consequently but indirectly - lift morale by securing the materialities of the population's existence. In this regard, although working alongside strategies designed to fortify 'the public mind', such interventions were not concerned directly with the installing of a template of conduct for the civilian or, critically, 'the blitzed-self'; but rather ensuring the security of vital infrastructure in emergency so as to maintain as much as possible the circulation of bodies and resources post-Blitz.

\section{Conclusion}

The atmospheric metaphors which opened this paper - 'a weather-map of popular feeling'; a 'war barometer' - are among many such metaphors encountered throughout MO's writing on morale. ${ }^{25} \mathrm{We}$ are intrigued by this meteorological language - the climatic nature of MO's morale commentary - which operated as a rhetorical device for MO to powerfully illustrate an affective atmosphere produced by the morale of the population. It performed this work robustly, for in recommending that the government adopt a 'war barometer' - an instrument to measure and monitor atmospheric pressure - MO was able to present morale as an object of knowledge quite literally. The regular morale reports MO produced out of its fieldwork and museological collecting and collating practices were part of what Rodney Harrison has identified as MO's greatest innovation, its emphasis on 'new, collectivized forms of self-knowledge which sought to make the population self-governing' (2014: 242, emphasis in original).

In this way MO's presentation of an affective atmosphere posited morale as a reality, autonomous from those who would study it. However MO's evocations of an affective atmosphere also pertained to morale as it was realized as a field of intervention. In particular, the affective atmosphere seemed to gesture towards elements of Foucault's formulation of the milieu, which is 'a set of natural givens_rivers, marshes, hills' as well as 'a set of artificial givens'; which we have seen is defined as 'a certain number of combined, overall effects bearing on all 
who live in it' (2007: 21). On the one hand, an atmospherics of morale facilitated bio-political endeavours, for example, to protect and re-channel the energy of bodies, but there was also a second, critical dimension involved. MO analysis repeatedly acknowledged the weather itself as a powerful factor influencing the morale of the population at any given moment. ${ }^{26}$

Thus MO's meteorological formulation of morale was not strictly metaphorical, since social atmospherics were correlated to physical atmospherics. While it did not - could not - arrest the preponderance of MO's attention and form a key plank of its advisory output, it functioned to limit the influence of the political elite. MO was extremely forthcoming in acknowledging the principal, untouchable affect of the skies above: 'Weather is more important than Winston' (MO 1941, \#568: 70). The affective atmosphere was a climactic mode of expression for MO's dialogue with the wartime Ministry of Information. In evoking meteorology MO not only evoked morale as a domain that can be governed - it also allowed MO to make an inscription within this domain of contingency: of uncertainty and unpredictability, of the ungovernable and the unmanageable. Perhaps, too, it opened space for the inscription of civilian voices within centres of calculation, which registered the panic evacuations, hysteria and neurosis of blitzed populations as symptoms of radical contingency. As Harrisson plainly recorded: 'This disaster comes from the skies, in a random 'senseless' way, which seems basically insane to many working people' (MO 1941, \#926: 5).

Received: 2 September 2013

Finally accepted: 15 January 2015

\section{Notes}

1 On 'atmosphere' as the ambience in which one feels the affects of others, see Brennan (2004: 1).

2 For a discussion of this dimension of liberal rule in the context of native policy, see Dibley (2014).

3 Hubble (2006: 167) observes that the first MO report for the Mol in September 1939 was on the subject of Ministry posters. It appears that it was not until 30 April 1940 that MO started to produce dedicated reports on general morale (MO 1941, \#568: 68), and on 18 May 1940 the organization commenced a series of daily morale reports which later evolved into weekly reports.

4 For historical overviews of MO, see Lander and Brook (no date), Jeffrey (1978), Calder (1985), Summerfield (1985), Pickering and Chaney (1986), Marcus (2001), Highmore (no date; 2002) and Hubble (2006). For a biography of Harrisson, see Heimann (1998). Also see Harrisson's own narrative of the history and operations of the organization in a transcript for a radio 'broadcast for Far East' entitled 'Mass-Observation \& How It Works' (MO 1942, \#1025: 1). It should be noted that the undertaking of this work with the Mol was controversial within MO ranks. It was the final straw for Madge, who parted company with Harrisson and MO, and took up work with Keynes at the Treasury. See Hubble (2001; 2006: 196).

5 Hubble (2006: 166-87) offers a close chronological account of the contracts and arrangements between $\mathrm{MO}$ and the Mol for this period. The professional relationship between the two organizations was not straightforward, and the commissioning of $\mathrm{MO}$ (for morale and other work) proceeded in a sporadic and intermittent fashion. Hubble describes how Harrisson carried out this work while engaging in ongoing negotiations to secure future work with the Ministry, and clarifies that while MO worked in various capacities for the Ministry for the first two years of WWII, the organization was 'only under a full-time contract from 6 April 1940 to 30 September 1941' $(174,187)$.

6 For a related discussion of the ways in which anthropological experts and practices of collection were imbricated in relations of government see Bennett, Dibley and Harrison (2014). Also see Dibley (2005). 
7 This phrase is from a MO File Report (MO 1940, \#286: 12).

8 While italics have been retained, emphasis such as underlining and capitalization has been omitted from the quotations of MO archival material throughout this paper.

9 In The Insecurity of Territory Paul Virilio writes: 'Total war was a threshold for our civilization to the extent that it was the first global aerial war' (cited in James 2007: 78).

10 For a history of the Mol see McLaine (1979). On centres of collection and calculation see Latour (1987: chapter 6) and Miller and Rose (2008: chapter 2).

11 The same document reported the problem faced by the Mol as 'one of the deepest and most complex ... in the world to-day; the problem of understanding and getting into contact with the underlying mass ideas of ultra-civilised working men' (MO 1940, \#298: 11). The implication here would seem to be that beneath the surface of 'the ultra-civilised' lies an irrational, primitive depth. The establishment of a primitive structure as the kernel of modern subjectivity is a key development for British Freudians. It might be said that this relativizing gesture - that moderns and non-moderns share a primitive kernel of subjectivity - established a connection between the knowledge practices of $\mathrm{MO}$ and formulations of colonial governmentality. See note 26 .

12 Freud, it will be recalled, was the self-described 'conquistador' who discovered the workings of that great 'dark continent', the unconscious. Gurney $(1997: 288)$ has suggested that Freud's 1921 work Group Psychology and the Analysis of the Ego 'uncritically adopted many of [Gustave] Le Bon's ideas, including the supposed similarity between the "group mind" and "the mental life of primitive people and of children"' The relationship between 'the public mind' of MO and the 'group mind' of Freud and Le Bon may repay attention. Le Bon and Freud's work on crowds would also bear upon the critical importance of crowds for $\mathrm{MO}$, among whose files can be located at least two reports filed by participant observers at political rallies, celebrating 'group feeling' and 'the crowd as a united whole' (MO 1940, \#345: [1]), and defining 'a successful mass meeting' as one where there is 'only one type of person; the type for which the meeting has its message' (MO 1940, \#298: 9).

13 For a critical engagement of MO's methodology by a contemporary, see Firth (1939).

14 Liz Stanley described Mass-Observation as 'a radical social science research organization on the borders and "other" to institutionalised sociology' (2008: 536). See Osborne and Rose (1999) for conceptual distinctions between the notion of 'opinion' and 'attitude' in the British social sciences of the 1930s and 1940s. For an account of the development of $\mathrm{MO}$ methods in relation to the emergence of various disciplinary formations in the British social sciences see Stanley $(2001 ; 2008)$. For accounts of the development of the social survey see Bulmer (1985), Bulmer, Bales and Sklar (1991) and Osborne and Rose (1997). For key statements on 'public opinion' in social theory see Habermas (1970) and Bourdieu (1990). See Savage $(2008 ; 2010)$ for an account of how technical expertise associated with the social sciences correlated with the rise of a technical class-fraction in post-war Britain. This was a movement in which he attributes $\mathrm{MO}$ a not insignificant role.

15 In Harrisson's work, the political elite are repeatedly upbraided for their disconnection with 'that vast majority' of the population that 'left school at 14' (MO 1939, \#A16: 3). George Orwell displayed a certain ambivalence towards MO's vigorous criticism of the ruling classes, implying there may be certain ideological blind spots in the organization's conception of civil society. Orwell ([1940] 1998: 17) suggests that just as MO's first publication May the Twelfth failed to register the existence of any 'royalist sentiment' in Britain at all, War Begins at Home is similarly unperceptive, as 'the one thing that the compilers do not seem to have encountered is the sentiment of patriotism'. 
16 The emotions and dispositions referred to here are sourced from a major MO report submitted to Home Intelligence's Mary Adams (1941, \#568: 3, [72], 58, 56, 56, [84]).

17 The close correlation suggested in this paragraph between the notions of Foucault's biopower and Marx's labour-power is drawn from Virno (2004: 81-4). For another example of a bio-political intervention in the interests of efficiency, see Jones (2006) on government and industry measures to protect productivity levels from the interruptions caused by air raid warnings.

18 See, for example, 'Report on Female Attitude to Compulsion' (MO 1941, \#919) and 'ManPower and Conscription' (MO 1941, \#1009).

19 The case for compulsory fire-spotting was taken to the public sphere. In a draft for an article to appear in the Tribune, an MO author argued that 'when it comes to securing effective action in the middle of the greatest war in history it is sometimes better to make people's minds up for them on the major questions of policy'. Lamenting the cost of having failed to institute compulsory forms of fire-watching the article continued: 'Large parts of the cities of London and Manchester have already been burnt down for the sake of the voluntary principle. How much more damage is it to be allowed to do?' (MO 1941, \#916: 1-2).

20 Bennett $(2009 ; 2013)$ deploys this distinction between public and milieu to investigate how museum/field relations are implicated in modes of government that target colonial and metropolitan populations in distinctly different ways. The contention of this paper is that the strategies of the public and the milieu are simultaneously directed at the same population, in this case, the working-class inhabitants of provincial cities.

21 In the introduction to a collection of daily and weekly morale reports by the Mol's Home Intelligence division from Britain's Public Record Office, Addison notes that MO's reports on 'conditions in the immediate aftermath of air-raids ... are strongly reflected in Home Intelligence reports for the winter of 1940-41' (1979: [n.p.]). See also Harrisson's ([1976] 2010) retrospective analysis of the Blitz.

22 For an account of class differences and 'social climbing' by Harrisson, see his essay 'Notes on Class Consciousness and Class Unconsciousness' (1942). On women's war experience, see Sheridan's anthology of excerpts from women's MO diaries and responses (2000). Within MO's volunteer panel, there were intersecting tensions around questions of class and gender, with Sheridan remarking on the 'class snobbery' that can be seen in the writing of some (primarily middle-class) MO correspondents (10).

23 There are parallels here between the description of 'the shock' of the air raid as a 'shattering psychological blow' and the impact of colonization on the indigene and the radical upheaval of the native quotidian. Here, similarly, those figured with limited material and intellectual resources were posited as vulnerable to psychological collapse in the face of crisis. The link here is W. H. R. Rivers, whose work on 'culture contact' in Melanesia and on shell-shock in WWI soldiers established a universal primitive core to subjectivity that was revealed, and to which subjects reverted, in times of extreme crisis. See Kuklick (1991).

$24 \mathrm{MO}$ reports also identified 'positive correlation between the survival of working class leisure institutions and high civilian morale' (Beaven and Griffiths 1999: 82). In relation to the deployment of leisure infrastructure, however, $\mathrm{MO}$ again found post-Blitz governance wanting. For example, one report noted that 'in post-blitz situations the function of entertainment in keeping up morale has sometimes been vigorously ignored. In one city the Chief Constable compulsorily closed every place of entertainment, including private dances, after some raids' (MO [1941], Home Propaganda: 47). Hence, the report recommended that, if the pub wasn't damaged, it ought to be open, and, in so doing, involves the bio-politics of soporifics in the management of civilian morale. Beaven and Griffiths (1999) also investigate drinking and high morale as reported by MO. 
For example: 'The atmosphere of ordinary Britain' is set against the Minister of Information Mr. Duff Cooper's 'atmosphere' of 'Downing Street and Dorchester' (MO 1940, \#286: 12); air raid evacuees are described as 'carry[ing] with them...an atmosphere of having come from a sort of inferno' (MO 1940, \#449: 7); and one report ruefully lamented 'the dull dull grey which everyday is gradually becoming' (MO 1940, \#508: 4).

The organization's 1942 publication People in Production registered the critical significance of the weather for morale: 'in detailed morale studies made by Mass-Observation over the past two years, we have found that over a period of time the two things which have most important bearing on short-term depression and cheerfulness are weather and health' (MO 1942, People in Production: 203). War news follows these two factors in the short term, although it is clarified that 'in the end cumulatively it naturally outweighs the others'.

\section{References}

Addison, P. (1979) 'Introduction', in Great Britain, Ministry of Information, The British People and World War II: Home Intelligence Reports on Opinion and Morale, 1940-1944, Sussex, UK: Harvester Press Microform Publications / John Spiers, http://images.crl. edu/106.pdf, accessed 17 October 2012.

Beaven, B. and Griffiths, J. (1999) 'The Blitz, Civilian Morale and the City: MassObservation and Working-Class Culture in Britain, 1940-41', Urban History, 26(1) 71-88.

Bennett, T. (1995) The Birth of the Museum: History, Theory, Politics, London: Routledge.

(2004) Pasts Beyond Memories: Evolution, Museums, Colonialism, London: Routledge. [1 can see no reference to this in the text]

(2009) 'Museum, Field, Colony: Colonial Governmentality and the Circulation of Reference', Journal of Cultural Economy, 2(1) 99-116.

(2013) 'The "Shuffle of Things" and the Distribution of Agency', in R. Harrison, S. Byrne and A. Clarke (eds) Reassembling the Collection: Ethnographic Museums and Indigenous Agency, 39-59, Santa Fe, NM: SAR Press. [I can see no reference to this in the text]

Bennett, T., Dibley, B. and Harrison, R. (2014) 'Introduction: Anthropology, Collecting and Colonial Governmentalities', History and Anthropology, 25(2) 137-49.

Bourdieu, P. (1990) 'Opinion Polls: A Science without a Scientist', in In Other Words: Essays Towards a Reflexive Sociology, 168-74, Stanford, CA: Stanford University Press.

Brennan, T. (2004) The Transmission of Affect, Ithaca: Cornell University Press.

Bulmer, M. (ed) (1985) Essays on the History of British Sociological Research, Cambridge, UK: Cambridge University Press.

Bulmer, M., Bales, K. and Sklar, K. K. (eds) (1991) The Social Survey in Historical Perspective, 1880-1940, Cambridge, UK: Cambridge University Press.

Calder, A. (1985) 'Mass-Observation 1937-1949', in M. Bulmer (ed) Essays on the History of British Sociological Research, 121-36, Cambridge, UK: Cambridge University Press.

Deans, M. (1999) Governmentality: Power and Rule in Modern Society, London: Sage. 
Dibley, B. (2005) 'The Museum's Redemption: Contact Zones, Government, and the Limits of Reform', International Journal of Cultural Studies, 8(1) 5-27.

(2014) 'Assembling an Anthropological Actor: Anthropological Assemblage and Colonial Government in Papua', History and Anthropology, 25(2) 263-79.

Firth, R. (1939) 'An Anthropologist's View of Mass-Observation', Sociological Review, 31(2) 166-93.

Foucault, M. (2007) Security, Population, Territory: Lectures at the Collège de France, 1977-1978, London: Palgrave Macmillan.

(2008) The Birth of Biopolitics: Lectures at the Collège de France, 1978-1979, London: Palgrave Macmillan.

Gurney, P. (1997) "Intersex" and "Dirty Girls": Mass-Observation and Working-Class Sexuality in England in the 1930s', Journal of the History of Sexuality, 8(2) 256-90.

Habermas, J. (1970) 'The Scientization of Politics and Public Opinion', in Toward a Rational Society: Student Protest, Science, and Politics, 62-80, Boston: Beacon Press.

Harrison, R. (2014) 'Observing, Collecting and Governing "Ourselves" and "Others": MassObservation's Fieldwork Agencements', History and Anthropology, 25(2) 227-45.

Harrisson, T. (1942) 'Notes on Class Consciousness and Class Unconsciousness', Sociological Review, 34(3-4) 147-64.

(1971) 'The Mass-Observation Archive at Sussex University', Aslib Proceedings, 23(8) 398-411.

([1976] 2010) Living Through the Blitz, London: Faber and Faber.

Heimann, J. M. (1998) The Most Offending Soul Alive: Tom Harrisson and His Remarkable Life, Honolulu: University of Hawai'i Press.

Highmore, B. (no date) 'Everyday Life and the Birth of Mass Observation', Essays, Mass Observation Online, Adam Matthew Digital and the University of Sussex.

(2002) Everyday Life and Cultural Theory: An Introduction, London: Routledge.

Hubble, N. (2001) 'Charles Madge and Mass-Observation Are at Home: From Anthropology to War, and After', New Formations, 44, 76-89.

(2006) Mass Observation and Everyday Life: Culture, History, Theory, London: Palgrave Macmillan.

James, I. (2007) Paul Virilio, Abingdon, UK: Routledge.

Jeffery, T. (1978) Mass-Observation: A Short History, Stencilled Occasional Paper No. 55, Birmingham: Centre for Contemporary Cultural Studies, University of Birmingham. [You haven't referenced this in the text]

Jones, H. (2006) British Civilians in the Front Line: Air Raids, Productivity and Wartime Culture, 1939-45, Manchester, UK: Manchester University Press.

Joyce, P. (1999) 'The Politics of the Liberal Archive', History and the Human Science, 12(2) 35-49. 
Kuklick, H. (1991) The Savage Within: The Social History of British Anthropology 18851945, Cambridge, UK: Cambridge University Press.

Lander, B. and Brook, S. (no date) Mass Observation: An Historical Introduction, Essays, Mass Observation Online, Adam Matthew Digital and the University of Sussex.

Latour, B. (1987) Science in Action: How to Follow Scientists and Engineers Through Society, Cambridge, MA: Harvard University Press.

Mackay, R. (2002) Half the Battle: Civilian Morale in Britain during the Second World War, Manchester, UK: Manchester University Press.

Madge, C. and Harrisson, T. (1937) Mass-Observation, Mass-Observation Series No. 1, London: Frederick Muller.

Marcus, L. (2001) 'Introduction: The Project of Mass-Observation', New Formations, 44: 5-19.

Mass Observation (1939) 'Home or Foreign?', 17 April 1939, report \#A16, File Reports 1937-1972, Mass Observation Online, Adam Matthew Digital and the University of Sussex.

(1940) War Begins at Home, London: Chatto and Windus.

(1940) 'Morale Now (30/4/40)', 30 April 1940, report \#89, File Reports 1937-1972, Mass Observation Online, Mass Observation Online, Adam Matthew Digital and the University of Sussex.

(1940) 'A New Attitude to the Problems of Civilian Morale', 21 June 1940, report \#193, File Reports 1937-1972, Mass Observation Online, Adam Matthew Digital and the University of Sussex.

(1940) 'General Points in Morale', 22 June 1940, report \#222, File Reports 19371972, Mass Observation Online, Adam Matthew Digital and the University of Sussex.

(1940) 'Report from Mass-Observation on Morale Today, July 2nd 1940', 2 July 1940, report \#242, File Reports 1937-1972, Mass Observation Online, Adam Matthew Digital and the University of Sussex.

(1940) 'Prediction, Restriction and Jurisdiction', 18 July 1940, report \#286, File Reports 1937-1972, Mass Observation Online, Adam Matthew Digital and the University of Sussex.

(1940) 'Report on The-Rout-the-Rumour-Rally', 26 July 1940, report \#298, File Reports 1937-1972, Mass Observation Online, Adam Matthew Digital and the University of Sussex.

(1940) 'Woodford Rally Report', 13 August 1940, report \#345, File Reports 19371972, Mass Observation Online, Adam Matthew Digital and the University of Sussex.

(1940) 'What is Public Opinion?', 19 August 1940, report \#361, File Reports 19371972, Mass Observation Online, Adam Matthew Digital and the University of Sussex.

(1940) 'Second Weekly Report for Home Intelligence from Mass-Observation', 11 October 1940, report \#449, File Reports 1937-1972, Mass Observation Online, Adam Matthew Digital and the University of Sussex. 
(1940) 'Experiment in Gauging any Daily Morale Fluctuations', 30 October 1940, report \#473A, File Reports 1937-1972, Mass Observation Online, Adam Matthew Digital and the University of Sussex. [This doesn't seem to be referenced in the text]

(1940) 'Report on Coventry', 18 November 1940, report \#495, File Reports 19371972, Mass Observation Online, Adam Matthew Digital and the University of Sussex.

(1940) 'Provisional Principles for Home Planning', 28 November 1940, report \#507, File Reports 1937-1972, Mass Observation Online, Adam Matthew Digital and the University of Sussex.

(1940) 'The Ninth Weekly Report (week ending 29th Nov. 1940) for Home Intelligence from Mass-Observation', 29 November 1940, report \#508, File Reports 1937-1972, Mass Observation Online, Adam Matthew Digital and the University of Sussex.

(1941) Home Propaganda: A Report Prepared by Mass-Observation for the Advertising Services Guild, London: Advertising Service Guild.

(1941) 'Report from Mass-Observation on Fire Spotters and Compulsory A.R.P.', 3 January 1940, report \#536, File Reports 1937-1972, Mass Observation Online, Adam Matthew Digital and the University of Sussex.

(1941) 'Morale in 1941.......', 4 February 1941, report \#568, File Reports 1937-1972, Mass Observation Online, Adam Matthew Digital and the University of Sussex.

(1941) 'Preliminary Report on Morale in Glasgow', 7 March 1941, report \#600, File Reports 1937-1972, Mass Observation Online, Adam Matthew Digital and the University of Sussex.

(1941) 'Blitz Information', 14 July 1941, reports \#785-6, File Reports 1937-1972, Mass Observation Online, Adam Matthew Digital and the University of Sussex.

(1941) 'Article for Tribune on Evacuation', 8 October 1941, report \#916, File Reports 1937-1972, Mass Observation Online, Adam Matthew Digital and the University of Sussex.

(1941) 'Report on Female Attitude to Compulsion', 16 October 1941, report \#919, File Reports 1937-1972, Mass Observation Online, Adam Matthew Digital and the University of Sussex.

(1941) 'Summary of Talk to the British Psychological Society (July 1941) by Tom Harrisson', 26 October 1941, report \#926, File Reports 1937-1972, Mass Observation Online, Adam Matthew Digital and the University of Sussex.

(1941) 'Man-Power and Conscription', 26 December 1941, report \#1009, File Reports 1937-1972, Mass Observation Online, Adam Matthew Digital and the University of Sussex.

(1941) '“Answering You”: No. 23', [22 December 1941], report \#1026, File Reports 1937-1972, Mass Observation Online, Adam Matthew Digital and the University of Sussex.

(1942) People in Production, Harmondsworth: Penguin.

(1942) 'Mass-Observation and How It Works', 2 January 1942, report \#1025, File Reports 1937-1972, Mass Observation Online, Adam Matthew Digital and the University of Sussex. 
(1942) 'Mass-Observation', 2 September 1942, report \#1415, File Reports 19371972, Mass Observation Online, Adam Matthew Digital and the University of Sussex.

(1944) 'Mass-Observation and Home-Front History', 22 June 1944, report \#2116, File Reports 1937-1972, Mass Observation Online, Adam Matthew Digital and the University of Sussex.

McLaine, I. (1979) Ministry of Morale: Home Front Morale and the Ministry of Information in World War II, London: Allen and Unwin.

Miller, P. and Rose, N. (2008) Governing the Present: Administering Economic, Social and Personal Life, Cambridge, UK: Polity.

Miller, T. (2001) 'In the Blitz of Dreams: Mass-Observation and the Historical Uses of Dream Reports', New Formation, 44, 34-51.

Orwell, G. ([1940] 1998) 'Review of War Begins at Home, edited by Tom Harrisson and Charles Madge', in A Patriot after All: 1940-1941, vol. 12 of P. Davison (ed) The Complete Works of George Orwell, 17-8, London: Secker \& Warburg.

Osborne, T. and Rose, N. (1997) 'In the Name of Society: Three Theses on the History of Social Thought', History of the Human Sciences, 10(3) 87-104.

(1999) 'Do the Social Sciences Create Phenomena?: The Example of Public Opinion Research', British Journal of Sociology, 50(3) 367-96.

Pickering M. and Chaney, D. (1986) 'Democracy and Communication: Mass Observation 1937-1943', Journal of Communication, 36(1) 41-56.

Rose, N. (1990) Governing the Soul: The Shaping of the Private Self, London: Routledge. (1998) Inventing Ourselves: Psychology, Power, and Personhood, Cambridge, UK: Cambridge University Press.

Savage, M. (2008) 'Affluence and Social Change in the Making of Technocratic MiddleClass Identities: Britain, 1939-55', Contemporary British History, 22(4) 457-76.

(2010) Identities and Social Change in Britain since 1940: The Politics of Method, Oxford, UK: Oxford University Press.

Sheridan, D. (ed) (2000) Wartime Women: A Mass-Observation Anthology, London: Phoenix Press.

Stanley, L. (2001) 'Mass-Observation's Fieldwork Methods', in P. Atkinson, A. Coffey, S. Delamont, J. Lofland and L. Lofland (eds), Handbook of Ethnography, 92-116, London: Sage.

(2008) 'It Has Always Known, and We Have Always Been "Other": Knowing Capitalism and the "Coming Crisis" of Sociology Confront the Concentration System and MassObservation', Sociological Review, 56(4) 535-51.

Summerfield, P. (1985) 'Mass-Observation: Social Research or Social Movement?', Journal of Contemporary History, 20(3) 439-52.

Virno, P. (2004) A Grammar of the Multitude, New York: Semiotext(e). 


\section{Acknowledgements}

The research for this article was conducted as part of Museum, Field, Metropolis, Colony: Practices of Social Governance, an Australian Research Council Discovery project (Award Number DP110103776).

*Ben Dibley is a Research Associate at the Institute for Culture and Society, the University of Western Sydney. He has research interests in social and cultural theory, museums, colonialism and the environment. He has recent publications in New Formations, Museum and Society, Transformations, and Australian Humanities Review.

Institute for Culture and Society

University of Western Sydney

Parramatta Campus, Building EM

Locked Bag 1797

Penrith NSW 2751

Australia

Tel: +6196859524

Email: b.dibley@uws.edu.au

** Michelle Kelly is a Senior Research Officer and Project Manager at the Institute for Culture and Society, the University of Western Sydney, Australia. She has recent publications in Libraries, Literatures, and Archives (edited by Sas Mays, Routledge, 2014) and The Art of Engagement (edited by Elaine Lally, len Ang and Kay Anderson, UWA Publishing, 2011). In 2012 she was awarded her PhD from the Department of English at the University of Sydney.

Institute for Culture and Society

University of Western Sydney

Parramatta Campus, Building EM

Locked Bag 1797

Penrith NSW 2751

Australia

Tel: +6196859600

Email: mi.kelly@uws.edu.au 